\title{
Depth perception in strabismus
}

\author{
DAVID B. HENSON AND DONNA E. WILLIAMS \\ From the Department of Optometry, University of Wales Institute of Science and Technology, \\ Cardiff CF1 $3 N U$
}

SUMMARY The monocular and binocular depth thresholds of strabismic subjects have been measured with a modified Howard-Dolman apparatus. Seven out of the 14 strabismic subjects tested were found to have binocular thresholds significantly higher than their monocular ones. These strabismic subjects all had small angles of deviation less than 8 prism dioptres and high acuities in both eyes.

The question whether strabismic subjects are able to utilise the cue of binocular parallax to see the world stereoscopically is of importance to both the clinician and the physiologist. While several researchers have reported stereopsis in strabismic subjects, ${ }^{1-8}$ no research project has specifically investigated this topic.

It is well known that many monocular cues exist to aid stereopsis. Thus a person who is stereoblind, that is, unable to use disparity information to appreciate depth, can often give a positive response in certain stereo tests. ${ }^{9}$ The ability of stereoblind observers to use monocular cues may even be better than normal owing to their greater reliance on this type of information.

The problem of being able to differentiate between monocular depth perception and stereopsis can be solved by measuring depth discrimination both monocularly and binocularly and taking any difference as a measure of stereopsis. None of the papers cited above have reported the use of this technique except that by $\mathrm{Kani}^{8}{ }^{8}$ whose work included one strabismic amblyope. Therefore the question whether strabismic subjects possess stereopsis is still open to debate.

In this paper we report on measures of the monocular and binocular depth threshold of a group of strabismic subjects using a series of stereo tests which include those commonly found in ophthalmic practices. The results are discussed in the light of detailed measurements of the binocular status of each subject.

\section{Subjects and methods}

The monocular and binocular depth thresholds of 9 normal and 14 strabismic subjects were measured

Correspondence to $\mathrm{Dr}$ D. B. Henson, UWIST, Arlbee House, Greyfriars Road, Cardiff CF1 3AE.

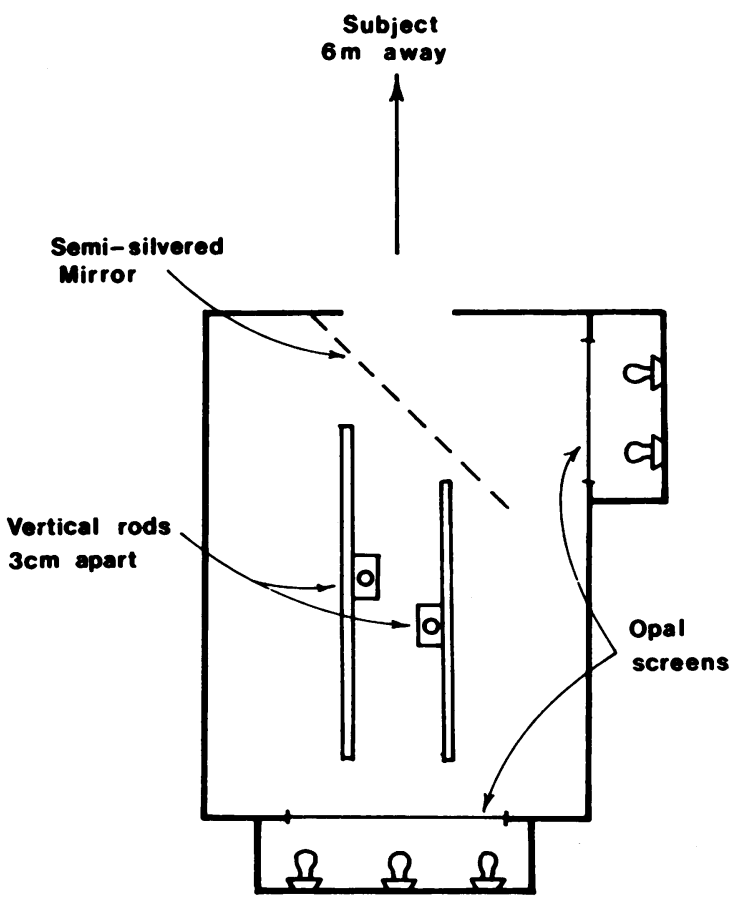

Fig. 1 A diagram of the modified Howard-Dolman apparatus as seen from above

with a modified Howard-Dolman apparatus. ${ }^{10}$ While the overall dimensions of the apparatus were the same as those in Howard's original instrument. certain modifications were included that allowed the exposure time and fixation to be controlled. A diagram of the apparatus is shown in Fig. 1. Situated between the front aperture and the $\frac{3}{8}$ in $(9.5 \mathrm{~mm})$ diameter rods was a semi-silvered mirror which reflected light from the side opal screen and transmitted light from the back opal screen. The lights 
Table 1 Result from the 7 strabismic subjects whose binocular depth thresholds were significantly lower than their monocular depth thresholds

\begin{tabular}{|c|c|c|c|c|c|c|c|c|c|}
\hline Subj. & $\begin{array}{l}\text { Age/Age } \\
\text { of onset }\end{array}$ & $R_{x}$ and V.A. & $\begin{array}{l}\text { Angle of Squint } \\
\text { (P.O.) } \\
S R_{x} \quad \subset R_{x}\end{array}$ & $\begin{array}{l}\text { Test and } \\
\text { density } \\
\text { of ARC }\end{array}$ & $\begin{array}{l}\text { Suppression } \\
\text { Scotoma }\end{array}$ & $\begin{array}{c}\text { Eccentric } \\
\text { Fixation } \\
\text { (P.D.) } \\
\end{array}$ & $\begin{array}{l}\text { Mon. } \\
\text { thres. } \\
(\mathrm{cm})\end{array}$ & $\begin{array}{l}\text { Bin. } \\
\text { thres } \\
(\mathrm{cm})\end{array}$ & $\begin{array}{l}\text { Stereothreshold } \\
\text { Titmus, Frisby, H-D } \\
\text { (s of arc) }\end{array}$ \\
\hline 1 & $\begin{array}{l}20.5 \\
2\end{array}$ & $\begin{array}{l}R+3.25 \text { DS } 6 / 5 \\
L+2.75 \text { DS } 6 / 5\end{array}$ & $\begin{array}{l}\text { D } 18 \text { eso } 3 \text { eso } \\
\text { Alt. } \\
\text { N } 20 \text { eso } 4 \text { eso }\end{array}$ & $\begin{array}{l}\text { ARC } \\
1.6\end{array}$ & & None & 11.95 & $\begin{array}{l}3.00 \\
3.98 x\end{array}$ & $40,15,10.6$ \\
\hline 2 & $\begin{array}{l}24.5 \\
?\end{array}$ & $\begin{array}{l}R-5.50 /-0.25 \times 56 / 5 \\
L-3.00 /-1.25 \times 1606 / 5\end{array}$ & $\begin{array}{ll}0 & 6 \text { exo } 6 \text { exo } \\
\text { Right } & \\
N & 6 \text { exo } 6 \text { exo }\end{array}$ & $\begin{array}{l}\text { ARC+ } \\
\text { MRC } \\
1.0\end{array}$ & & $?$ & 21.68 & $\begin{array}{l}4.73 \\
4.58 x\end{array}$ & $40,20,15.0$ \\
\hline 3 & $\begin{array}{l}20 \\
5\end{array}$ & $\begin{array}{l}R-1.75 /-0.25 \times 406 / 5 \\
L-2.50 /-0.50 \times 806 / 5\end{array}$ & $\begin{array}{l}\text { D } 3 \text { eso } 3 \text { eso } \\
\text { Left } \\
N \quad 3 \text { eso } 3 \text { eso }\end{array}$ & $\begin{array}{l}\text { ARC } \\
1.4\end{array}$ & & None & 22.13 & $\begin{array}{l}3.28 \\
6.75 x\end{array}$ & $40,25,11.5$ \\
\hline 4 & $\begin{array}{l}19.5 \\
6\end{array}$ & $\begin{array}{l}R-3.50 /-0.25 \times 256 / 5 \\
L-4.00 /-0.26 \times 1456 / 6\end{array}$ & $\begin{array}{l}\text { D } 14 \text { exo } 4 \text { exo } \\
\text { Left } \\
\text { N } 30 \text { exo } 8 \text { exo }\end{array}$ & $\begin{array}{l}\text { ARC } \\
1.8\end{array}$ & & 1 & 18.88 & $\begin{array}{l}5.87 \\
3.22 x\end{array}$ & $40,75,21.0$ \\
\hline 5 & $\begin{array}{l}19.5 \\
18\end{array}$ & $\begin{array}{l}R+0.50 /-0.50 \times 156 / 6 \\
L+0.75 /-0.50 \times 1656 / 6\end{array}$ & $\begin{array}{c}\text { D } 8 \text { exo } 8 \text { exo } \\
\text { Intermittent } \\
N 10 \text { exolo exo }\end{array}$ & NRC & & None & 14.44 & $\begin{array}{l}2.36 \\
6.12 x\end{array}$ & $40,15,8.6$ \\
\hline 6 & $\begin{array}{l}19.5 \\
4\end{array}$ & $\begin{array}{l}R+3.50 \text { DS } 6 / 5 \\
L+4.50 \text { DS } 6 / 6\end{array}$ & $\begin{array}{l}016 \text { eso } 0 \\
\text { Left } \\
N 20 \text { eso } 3 \text { eso }\end{array}$ & $\begin{array}{l}\text { ARC } \\
1.6\end{array}$ & & None & 13.35 & $\begin{array}{l}3.90 \\
3.42 x\end{array}$ & $80,35,15.0$ \\
\hline 7 & $\begin{array}{l}15 \\
2\end{array}$ & $\begin{array}{l}R+5.25 /-1.00 \times 1806 / 9 \\
L+4.75 \text { DS }\end{array}$ & $\begin{array}{l}\text { D } 12 \text { eso } 5 \text { eso } \\
\text { Right } \\
N 16 \text { eso } 6 \text { eso }\end{array}$ & $\begin{array}{l}\text { ARC } \\
1.4\end{array}$ & & None & 21.2 & $\begin{array}{l}2.75 \\
7.71 x\end{array}$ & $40,20,10.0$ \\
\hline
\end{tabular}

$\mathbf{R}_{\mathbf{x}}=$ Prescription for spectacles. $\mathbf{s} \mathbf{R}_{\mathbf{x}}=$ Without prescription for spectacles. $\mathbf{c} \mathbf{R}_{\mathbf{x}}=$ With prescription for spectacles. VA $=$ Visual acuity. $A R C=$ Abnormal retinal correspondence. $N R C=$ Normal retinal correspondence. $x=$ Multiplication.

behind these 2 opal screens were controlled by a timing circuit which allowed only 1 set to be on at any given time. Before the subject triggered the timing circuit the lights behind the side opal screen would be on and the subject would see a fine black cross which was attached to the front of the side opal. This cross, which provided the subject with a fixation point, was positioned so as to be in line with the centre of the right rod. On triggering the timing circuit the lights behind the rear panel would come on and those behind the side opal panel go off for a period of 2 seconds, enabling the subject to see the two vertical black rods. The intensity of the background screens, as seen by the subject, was $1.80 \times 10^{2} \mathrm{~cd} / \mathrm{m}^{2}$.

Subjects were carefully aligned 6 metres away from the stationary rod, their heads being kept stationary with the aid of a chin and forehead rest. A forced-choice technique was used to establish the depth thresholds. ${ }^{11}$

Three sets of readings were taken on each subject. The first of these was taken with the dominant or nondeviating eye only, the second set with both eyes, and the third set with the same eye as the first set. There was a half-hour break between each session. The experiment was conducted in this manner to establish whether there were any training or fatiguing effects.

The stereo acuity was also measured with the
Titmus and Frisby tests in the manner outlined in the instructions provided with each test.

In addition to measuring the depth thresholds the binocular status of the strabismic subjects was established with the following tests. Firstly, the objective angle of deviation was measured distance and near, with and without spectacle corrections, by a prism bar and cover test. The degree of eccentric fixation was measured by Haidinger's brushes in conjunction with a tangent screen. And the presence of abnormal retinal correspondence (ARC) or suppression was detected with a Bagolini striated lens in conjunction with a neutral density filter bar (in steps of $0.2 \mathrm{log}$ units), as described by Mallett. ${ }^{12}$

All normal subjects had acuities of $6 / 6$ or better in both eyes and wore their correcting spectacles (if any) throughout the duration of the experiment.

\section{Results and discussion}

The results from the strabismic subjects are given in Tables 1 and 2.

The stereo thresholds for the Titmus test were obtained from the data supplied with the test. The values for the Frisby test were obtained from the corrected tables published by Frisby.13 The monocular and binocular depth thresholds for each session on the Howard-Dolman apparatus were obtained both by calculation and by measurement 
Table 2 Results from the 7 strabismic subjects whose monocular and binocular depth thresholds were essentially the same

\begin{tabular}{|c|c|c|c|c|c|c|c|c|c|}
\hline Subj. & $\begin{array}{l}\text { Age/Age } \\
\text { of onset }\end{array}$ & $R_{x}$ and V.A. & $\begin{array}{l}\text { Angle of Squint } \\
\text { (P.D.) } \\
S R_{x} \quad \& R_{x}\end{array}$ & $\begin{array}{l}\text { Test and } \\
\text { density } \\
\text { of ARC }\end{array}$ & $\begin{array}{l}\text { Suppression } \\
\text { Scotoma }\end{array}$ & $\begin{array}{l}\text { Eccentric } \\
\text { Fixation } \\
\text { (P.D.) }\end{array}$ & $\begin{array}{l}\text { Mon. } \\
\text { thres. } \\
\text { (cm) }\end{array}$ & $\begin{array}{l}\text { Bin. } \\
\text { thres. } \\
\text { (cm) }\end{array}$ & $\begin{array}{l}\text { Stereothreshold } \\
\text { Titmus, Frisby, H-D } \\
\text { ( } s \text { of arc) }\end{array}$ \\
\hline 8 & $\begin{array}{l}21 \\
4\end{array}$ & $\begin{array}{l}R+1.50 /-0.75 \times 1656 / 9 \\
L+2.25 /-0.75 \times 606 / 5\end{array}$ & $\begin{array}{l}\text { D } 25 \text { eso } 12 \text { eso } \\
\text { Right } \\
N 25 \text { eso } 12 \text { eso }\end{array}$ & $\begin{array}{l}\text { ARC } \\
0.6\end{array}$ & & Mone & 12.2 & $\begin{array}{l}10.45 \\
1.17 x\end{array}$ & $800,-.-$ \\
\hline 9 & $\begin{array}{l}18 \\
0\end{array}$ & $\begin{array}{l}R-3.00 /-0.50 \times 156 / 5 \\
L-2.50 /-0.50 \times 306 / 5\end{array}$ & $\begin{array}{l}\text { D } 40 \text { eso } 35 \text { eso } \\
\text { Right } \\
\text { N } 35 \text { eso } 35 \text { eso }\end{array}$ & $\begin{array}{l}\text { ARC } \\
0.4\end{array}$ & & 1 & 16.08 & $\begin{array}{l}14.18 \\
1.13 x\end{array}$ &,,--- \\
\hline 10 & $\begin{array}{l}17 \\
3\end{array}$ & $\begin{array}{l}R+3.50 /-0.50 \times 306 / 9 \\
L+2.00 \text { DS }\end{array}$ & $\begin{array}{l}\text { D } 35 \text { eso } 25 \text { eso } \\
\text { Right } \\
\text { N } 35 \text { eso } 25 \text { eso }\end{array}$ & Sup & & 2 & 13.35 & $\begin{array}{l}13.80 \\
0.98 x\end{array}$ & $\because, \cdots$ \\
\hline 11 & $\begin{array}{l}50 \\
?\end{array}$ & $\begin{array}{l}R+5.75 /-0.50 \times 306 / 9 \\
L+5.50 /-1.00 \times 1756 / 6\end{array}$ & $\begin{array}{l}\text { D } 8 \text { eso } 8 \text { eso } \\
\text { Alt. } \\
\text { N } 12 \text { eso } 10 \text { eso }\end{array}$ & $\begin{array}{l}\text { ARC } \\
1.4\end{array}$ & 2 & Mone & 9.65 & $\begin{array}{l}12.00 \\
0.80 x\end{array}$ & $800,-,-$ \\
\hline 12 & $\begin{array}{l}18 \\
4\end{array}$ & $\begin{array}{l}R+3.00 /-0.50 \times 1806 / 9 \\
L+2.00 /-0.50 \times 1806 / 5\end{array}$ & $\begin{array}{l}\text { D } 12 \text { eso } 5 \text { eso } \\
\text { Right } \\
\text { N } 12 \text { eso } 5 \text { eso }\end{array}$ & $\begin{array}{l}\text { ARC } \\
0.8\end{array}$ & & None & 14.63 & $\begin{array}{l}13.58 \\
1.08 x\end{array}$ & $200,150,-$ \\
\hline 13 & $\begin{array}{l}35 \\
1\end{array}$ & $\begin{array}{l}R+3.50 /-0.25 \times 906 / 5 \\
L+4.00 /-0.50 \times 506 / 36\end{array}$ & $\begin{array}{l}010 \text { exo } 12 \text { exo } \\
\text { Left } \\
N 6 \text { exo } 6 \text { exo }\end{array}$ & Sup & & $?$ & - & - &,,-- \\
\hline 14 & $\begin{array}{l}55 \\
0\end{array}$ & $\begin{array}{l}R+5.50 /-0.75 \times 106 / 6 \\
L+6.25 D S \quad 6 / 18\end{array}$ & $\begin{array}{l}08 \text { exo } 8 \text { exo } \\
\text { Left } \\
N 10 \text { exo } 10 \text { exo }\end{array}$ & Sup & & 2 & - & - & $400,340,-$ \\
\hline
\end{tabular}

Abbreviations as in Table 1.

from an ogive. (The techniques used to calculate the stereo threshold by both calculation and measurement are fully described in Woodworth and Schlosberg. ${ }^{11}$ ) In the majority of cases these 2 techniques yielded similar results. In the few cases when they did not the data from the ogive were used. The final monocular threshold was taken as an average of the values obtained from the 2 monocular sessions.

Seven of the 14 strabismic subjects who took part in this project showed a binocular depth threshold significantly better than their monocular thresholds with the Howard-Dolman apparatus. Their binocular thresholds ranged from 8.6 to 21 seconds of arc. The average binocular threshold for normal subjects with this apparatus was 5.8 seconds of arc (SD 2.2). Thus the strabismic subjects had in all cases thresholds above the normal.

A graph of the ratio of the monocular threshold to the binocular threshold versus the angle of deviation is given in Fig. 2. It can be seen from this figure that it is only those subjects with angles of deviation which fall in the microtropic range (1-5 degrees according to Lang $^{14}$ ) who had fairly good stereo acuities. The habitual angles of deviation of these subjects did not exceed 6 prism dioptres of esotropia and 8 prism dioptres of exotropia.

All of the subjects with binocular thresholds significantly above their monocular acuities had no more than a 1-line difference between the visual acuities of the 2 eyes, the better eye having a mini- mum acuity of $6 / 6$. This parameter is not, however, a good indicator of stereo acuity in strabismic subjects, as several subjects with very poor stereo acuity also had high visual acuities in both eyes. It does seem, however, that strabismic subjects with low visual acuity in one or both eyes are unlikely to have a high stereo acuity.

It can also be seen from Fig. 2 that while all subjects with high stereo acuity had a microtropia

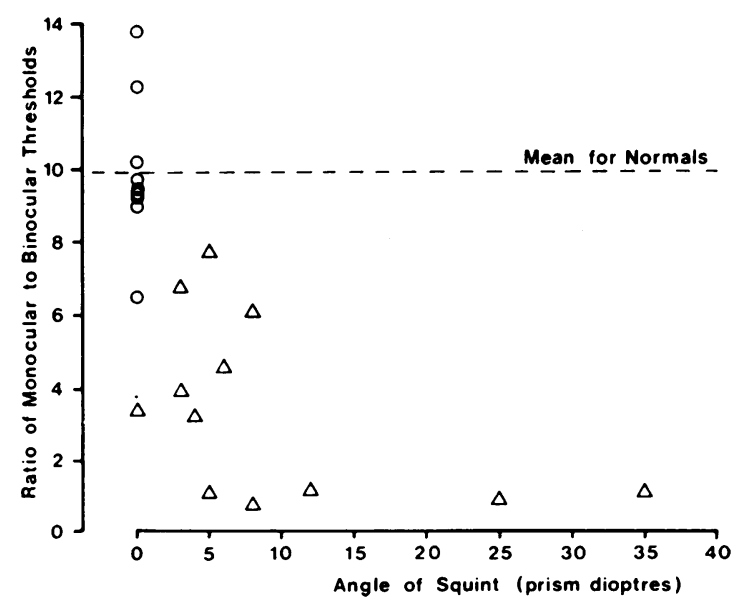

Fig. 2 The ratio of the monocular to binocular depth thresholds for the 9 normal subjects $(\bigcirc)$ and the 14 strabismic subjects $(\triangle)$ 


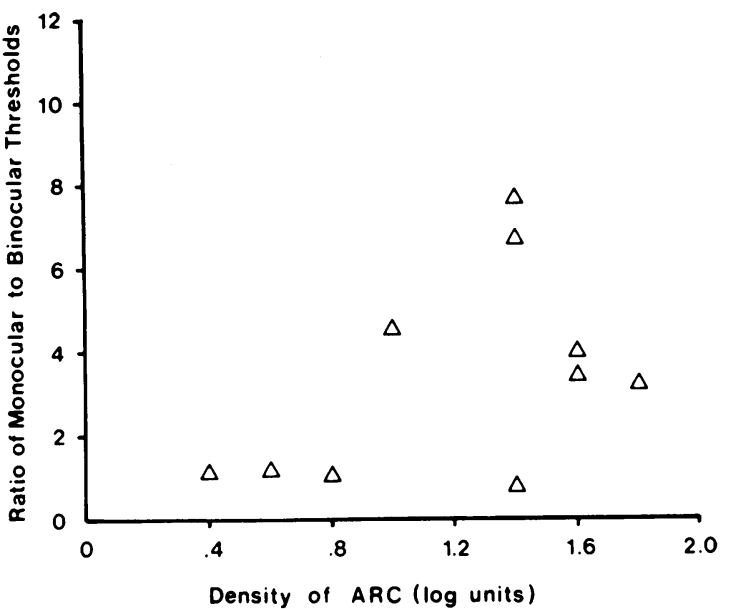

Fig. 3 The ratio of monocular to binocular depth threshold versus density of $A R C$ in the strabismic subjects

there were 2 subjects with microtropia who did not have a high stereo acuity.

Five of the 7 subjects with high stereo acuities gave responses of harmonious abnormal retinal correspondence (ARC) whilst the sixth subject gave a mixed response of normal retinal correspondence (NRC) and ARC and the seventh subject showed NRC. The subject who showed NRC had only recently been diagnosed as strabismic.

A graph of the ratio of monocular to binocular depth threshold versus the density of ARC is given in Fig. 3. There is a correlation coefficient of 0.48 between these 2 measures, a finding which gives support to Mallett, ${ }^{7}$ who stated that where the angle of deviation is small the ARC is generally well established and the binocularity of a high order. Of the 7 remaining subjects who had either gross stereopsis or no stereopsis at all 4 had only lightly ingrained ARC while the remaining 3 showed obligatory suppression.

The average monocular depth threshold for the 14 strabismic subjects was found to be $15.8 \mathrm{~cm}$ (SE 1.1), while that for the normals was 12.9 (SE $0 \cdot 8$ ). These values are not significantly different at the $10 \%$ level. Dividing the strabismic subjects into those with stereopsis and those without yields values of $17.7 \mathrm{~cm}(\mathrm{SE} 1.6)$ and $13.2 \mathrm{~cm}(\mathrm{SE} 1.1)$ respectively. The average monocular depth thresholds were also measured in 2 monocular subjects and found to be $23.3 \mathrm{~cm}$ and $15.3 \mathrm{~cm}$. There does not, therefore, seem to be any evidence within this experiment to support the idea that those subjects with deficient stereopsis have developed their abilities to use monocular cues beyond that of normal persons.
Three different tests were used to measure the stereo acuity in the strabismic subjects, namely, the Howard-Dolman test, the Titmus test, and the Frisby test. The stereo acuities recorded with the Howard-Dolman apparatus were higher than those recorded with the Titmus and Frisby tests. This difference could be due either to the difference in the nature of the tests or to the difference in the testing distances.

Both the Titmus and Frisby tests correlated fairly well with the Howard-Dolman test in that all of the strabismic subjects with stereopsis obtained fairly good stereo acuity measures with both the Titmus and Frisby tests. Although the Titmus test could distinguish strabismic subjects with stereopsis from those without, it was unable to distinguish strabismic subjects with stereopsis from normal persons, as the limiting threshold of this test is $\mathbf{4 0}$ seconds of arc. The highest disparity settings of the Titmus test $(400+800$ seconds) seem to be of little value, as most people can distinguish which is the eccentric spot with one eye closed and the practitioner has no evidence as to whether the subject is responding to this cue or to the correct one. ${ }^{9}$

\section{Conclusions}

Seven out of 14 strabismic subjects were found to have stereo acuities significantly better than their monocular depth thresholds when tested with a modified Howard-Dolman apparatus. None of the strabismic subjects had stereo acuities as high as the average for normal persons measured with the same instrument. The strabismic subjects with stereopsis all had angles of deviation below 8 prism dioptres and high monocular acuities. The results from the Titmus and Frisby stereotests correlated fairly well with the results from the HowardDolman test. The monocular depth threshold of strabismic subjects was found to be no different from that of normal persons.

\section{References}

${ }^{1}$ Naylor E, Stanworth A. Binocular depth perception in small angled strabismus. Br J Ophthalmol 1959; 43: 662-9. ${ }^{2}$ Helveston E, Von Noorden G. Microtropia. Arch Ophthalmol 1967; 78: 272-81.

${ }^{3}$ Parks M. Stereoacuity as an indicator of bifixation. International Strabismus Symposium, Giessen, August 1966. Basel, 1968: 258:60.

${ }^{4}$ Parks M. Seminar on strabismus. Transactions of the 19th Annual Session, New Orleans Academy of Ophthalmology. St. Louis, 1970; 121-53.

${ }^{5}$ Christian P. The management of small-angled esotropia with abnormal retinal correspondence. Am Orthopt $J$ 1971; 21: 92-5.

${ }^{6}$ Epstein D, Tredici T. Microtropia in flying personnel. Am J Ophthalmol 1973; 76: 832-41. 
${ }^{7}$ Mallett R. Aspects of investigation and treatment of strabismus. Ophthalmic Optician 1977; 17: 432-3.

${ }^{8} \mathrm{Kani}$ W. Stereopsis and spatial perception in amblyopes and uncorrected ametropes. Br J Ophthalmol 1978; 62: 756-62.

${ }^{9}$ Reinecke R, Simmons K. A new stereotest for amblyopia screening. Am J Ophthalmol 1974; 78: 714-21.

${ }^{10}$ Howard $\mathrm{H}$. A test for the judgment of distance. Am J Ophthalmol 1919; 2: 656-75.
${ }^{11}$ Woodworth RS, Schlosberg H. Experimental Psychology, revised 1st ed. New York: Holt, Reinehart and Winston, 1964: 200-10.

${ }^{12}$ Mallett $R$. Neutral density filters in the diagnosis of sensory anomalies. Ophthalmic Optician 1975; 15: 533-5.

${ }^{13}$ Frisby JP. Note on the Frisby stereo test. Optician 1 June 1979.

${ }^{14}$ Lang J. Strabismus. London: Kimpton, 1969: 160-4. 